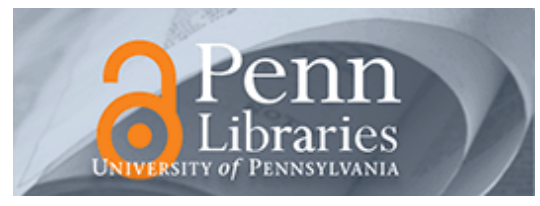

University of Pennsylvania

ScholarlyCommons

Accounting Papers

Wharton Faculty Research

$2-2010$

\title{
In Defense of Fair Value: Weighing the Evidence on Earnings \\ Management and Asset Securitizations
}

\author{
Mary Barth \\ Daniel J. Taylor \\ University of Pennsylvania
}

Follow this and additional works at: https://repository.upenn.edu/accounting_papers

Part of the Accounting Commons, and the Economics Commons

\section{Recommended Citation}

Barth, M., \& Taylor, D. J. (2010). In Defense of Fair Value: Weighing the Evidence on Earnings Management and Asset Securitizations. Journal of Accounting and Economics, 49 (1-2), 26-33. http://dx.doi.org/

10.1016/j.jacceco.2009.10.001

At the time of publication, author Daniel Taylor was affiliated with Stanford University. Currently (October, 2016), he is a faculty member at the Accounting Department at the University of Pennsylvania.

This paper is posted at ScholarlyCommons. https://repository.upenn.edu/accounting_papers/27

For more information, please contact repository@pobox.upenn.edu. 


\title{
In Defense of Fair Value: Weighing the Evidence on Earnings Management and Asset Securitizations
}

\author{
Abstract \\ Dechow, Myers, and Shakespeare (DMS, 2009) find a negative relation between income from \\ securitization activities and income from non-securitization activities. DMS interprets this finding as \\ indicating that managers use the flexibility available in fair value accounting rules to smooth earnings. We \\ clarify the role of fair value in accounting for asset securitizations, discuss alternative explanations for \\ the evidence presented in DMS, and offer suggestions for future research. We caution against inferring \\ the desirability of any particular accounting method from earnings management research.

\section{Keywords} \\ asset securitizations, securitization income, earnings management, fair value \\ Disciplines \\ Accounting | Economics

\section{Comments} \\ At the time of publication, author Daniel Taylor was affiliated with Stanford University. Currently (October, \\ 2016), he is a faculty member at the Accounting Department at the University of Pennsylvania.
}




\title{
In Defense of Fair Value:
}

\section{Weighing the Evidence on Earnings Management and Asset Securitizations}

\author{
Mary Barth \\ mbarth@stanford.edu \\ Daniel Taylor \\ djtaylor@stanford.edu \\ Graduate School of Business \\ Stanford University \\ 518 Memorial Way \\ Stanford, CA 94305
}

September 2009

We thank Ian Gow, S.P. Kothari (editor), David Larcker, Tom Linsmeier, Linda Myers, Cathy Shakespeare, John Smith, and seminar participants at 2008 JAE Conference for helpful comments. Daniel Taylor gratefully acknowledges funding from the Deloitte Foundation. 


\title{
In Defense of Fair Value: \\ Weighing the Evidence on Earnings Management and Asset Securitizations
}

\begin{abstract}
:
Dechow, Myers, and Shakespeare (2009, DMS) finds a negative relation between income from securitization activities and income from non-securitization activities. DMS interprets this finding as indicating that managers use the flexibility available in fair value accounting rules to smooth earnings. We clarify the role of fair value in accounting for asset securitizations, discuss alternative explanations for the evidence presented in DMS, and offer suggestions for future research. We caution against inferring the desirability of any particular accounting method from earnings management research.
\end{abstract}

Key words: asset securitizations, securitization income, earnings management, fair value 


\section{In Defense of Fair Value: Weighing the Evidence on Earnings Management and Asset Securitizations}

\subsection{Introduction}

Dechow, Myers, and Shakespeare (DMS, 2009) studies earnings management associated with gains from asset securitizations. Asset securitizations provide a potentially powerful setting in which to study earnings management because accounting for income from asset securitizations requires the exercise of judgment and discretion. ${ }^{1}$ In addition, as DMS points out, asset securitizations are an increasingly important economic activity that is in focus in the current financial crisis, largely because of the questionable accounting rules that apply to securitizations. Thus, how to account for asset securitizations is an interesting and timely issue and deserves the scrutiny of academic research. DMS identifies three research objectives related to studying income from asset securitizations - to determine whether managers use discretion in estimating fair value to smooth earnings, to examine the sensitivity of CEO pay to securitization gains, and to investigate whether boards of directors play a monitoring role in determining the size of gains from securitizations or the sensitivity of CEO pay to such gains.

Regarding whether managers use asset securitizations to smooth earnings, DMS finds a negative relation between income from securitization activities and income from nonsecuritization activities. DMS interprets this evidence as indicating that managers use the discretion afforded by fair value accounting to smooth earnings. Regarding the sensitivity of CEO pay, DMS finds that CEO pay is equally sensitive to securitization income and nonsecuritization income. DMS interprets this evidence as indicating that compensation committees treat securitization income as they treat other components of income. Regarding monitoring by

\footnotetext{
${ }^{1}$ We follow DMS and refer to income from asset securitizations as "gains from asset securitizations" and "gain on sale” accounting. However, not all asset securitizations result in gains. DMS reports that $76 \%$ of the study's observations are gains, $15 \%$ are losses, and $9 \%$ have zero income effect.
} 
directors, DMS finds little evidence that board monitoring affects earnings management or the sensitivity of CEO pay to securitization gains. We discuss several alternative explanations for the evidence and offer suggestions for future research. We conclude with a cautionary note about inferring the desirability of a particular accounting method from evidence of earnings management.

The objective of DMS is to establish that managers "use the discretion obtained from fair value accounting rules” to manage income from securitizations. This is an ambitious objective because it requires not only documenting the presence of earnings management, but also identifying fair value as the source of that earnings management. This is particularly ambitious because fair value plays only an indirect role in determining the amount of securitization income. Documenting earnings management associated with asset securitizations is a contribution in itself, even without identifying the source. Although DMS’s findings are consistent with earnings management, the findings do not speak to whether discretion in fair value estimates is the source of earnings management. Seeking to establish that discretion in fair value estimates is the source of earnings management and not convincingly doing so limits the impact of the study.

The remainder of the paper proceeds as follows. Section 2 discusses fair value accounting in the context of asset securitizations. Section 3 reviews the evidence presented in DMS and provides alternative interpretations. Section 4 discusses the role of earnings management research in informing standard setting, and Section 5 concludes.

\subsection{Accounting for Securitizations}

Fair values can be used for initial measurement or subsequent measurement of financial statement items, i.e., assets, liabilities, and equity. The phrase "fair value accounting” applies when fair value is used for initial measurement and subsequent measurement, and changes in the 
fair value amounts are recognized in net income. That is, under fair value accounting, at each financial statement date the item is remeasured to its fair value at that date. Using fair value only at initial measurement is not fair value accounting because when a financial statement item is initially recognized, and hence measured, there typically is a transaction in which fair value is the same as the item's cost, i.e., the transaction price. Thus, fair value at initial measurement can simply be the starting point for historical cost-based subsequent measurement. Much of the criticism of fair value accounting in the popular press is directed at subsequent measurement at fair value. It is not directed at the transaction-based initial measurement that applies to asset securitizations, which is the focus of DMS.

Fair value accounting is not applied to asset securitizations under U.S. GAAP. In fact, the role of fair value estimates in accounting for asset securitizations is indirect. As DMS notes, Statement of Financial Accounting Standards No. 140 (SFAS 140; FASB, 2000) requires that the carrying amount of the total assets securitized is allocated between the portion securitized and the interest in the assets retained by the securitizer based on the relative fair values of two portions. The fair value of the portion securitized typically equals the transaction price. The fair value of the retained interest must be estimated, which is where most of the fair value estimation discretion comes in. In the vast majority of securitization transactions, the sum of these two amounts exceeds the carrying amount of the total securitized assets immediately prior to the transaction, which results in a securitization gain. The gain relates only to the securitized portion, not to the retained interest. In contrast to DMS's statement that “....retained cash flows must be recorded at fair value...” (emphasis in the original), the retained interest is not initially measured at fair value in the securitizer's statement of financial position. SFAS 140 requires it 
to be initially measured at an allocated portion of the carrying amount immediately prior to the transaction. $^{2}$

The subsequent measurement of the retained interest depends on its nature and the entity's choice of accounting method. If the retained interest is in security form, then it will be classified as held-to-maturity, available-for-sale, or trading in accordance with SFAS 115 (FASB, 1993). Held-to-maturity securities are subsequently measured at historical cost, available-for-sale securities are subsequently measured at fair value with fair value changes recognized in other comprehensive income and impairment recognized in net income, and trading securities are measured at fair value with fair value changes recognized in net income. If the retained interest is not in security form, it is measured depending on the nature of the asset, typically at historical cost. ${ }^{3}$ See Ryan (2008) for a comprehensive discussion of accounting for asset securitizations. However, how the retained interest is subsequently measured is not relevant to the determination of securitization income - only initial measurement of the retained interest affects the securitization gain or loss.

Because the fair value of the retained interest only indirectly affects the magnitude of the gain, discretion in estimating the fair value provides only a limited opportunity for earnings management associated with securitization income. The likely greater opportunity for earnings management stems from the decision to securitize the assets in the first place (Dechow and Shakespeare, 2009). Ironically, if fair value accounting were applied to the securitized assets, rather than historical cost-based accounting, the opportunity for earnings management associated with asset securitizations would be substantially reduced. This is because any unrealized gains

\footnotetext{
2 SFAS 166 (FASB, 2009) requires retained interests in securitized assets to be measured initially at fair value, but SFAS 166 was not in effect during DMS's sample period.

${ }^{3}$ For example, Citigroup's 2004 annual report explains that Citigroup classifies some retained interest as consumer loans measured at historical cost, some as trading account assets, and some as available for sale investments.
} 
on the securitized assets would have been recognized in net income as they occurred, rather than only being recognized when the entity chooses to enter into a securitization transaction that triggers their recognition. That is, if fair value accounting were used for the securitized assets prior to the securitization transaction, managers would not be able to increase income by "cherry picking” those assets when the historical cost-based carrying amount is less than fair value.

DMS seeks to study discretion associated with gains from asset securitizations. There are three levels of discretion relating to these gains. The first is the firm's decision whether to securitize assets and, if so, which assets to securitize. This decision affects the amount of securitization income because if the securitization transaction qualifies for sale treatment, the firm recognizes the difference between the value of the portion of the assets sold and the carrying amount of that portion; if it does not qualify for sale treatment, there is no income effect of the transaction. Because most securitized assets are measured based on historical cost and not at fair value, sale treatment enables recognition of previously unrecognized gains or losses. The second level is the firm's decision whether to structure the securitization to meet the sale treatment requirements. This level is closely related to the first, and, as DMS notes, most securitization transactions are structured to meet the requirements. As a practical matter, most firms that do not seek to recognize income from the securitization do not engage in securitization transactions. The third level is determining the amount of the gain or loss.

Even though DMS seems to focus on the third level, because it is the only level affected by fair value estimates, DMS does not attempt to distinguish this level of discretion from the others. Thus, from DMS one cannot discern whether the observed earnings management results from discretion in determining which assets to securitize, if any, or discretion in estimating the 
amount of the gain. ${ }^{4}$ Both are forms of earnings management, but one is associated with cherry picking unrecognized gains on assets measured based on historical cost and the other is associated with using discretion to affect fair value estimates. These are very different sources of earnings management.

\subsection{Reviewing the Evidence and Alternative Explanations}

DMS conducts three sets of tests to address the three objectives. The first set tests whether securitization income is negatively correlated with pre-securitization income, i.e., whether securitization income is associated with earnings smoothing. The second set tests whether CEO pay is equally sensitive to securitization and pre-securitization income. The third set tests whether characteristics of the board of directors are associated with earnings smoothing and the sensitivity of CEO pay to securitization income.

\subsection{Negative Relation between Securitization Income and Pre-Securitization Income}

Recognizing that earnings management requires both opportunity and incentive, DMS focuses on two settings in which the incentives for earnings management are thought to be particularly strong. The first setting is when the firm has low pre-securitization income; DMS predicts that "when pre-securitization earnings are high, managers have less incentive to record gains and could even prefer to report a loss.” The second setting is when pre-securitization income is below last year's pre-securitization income; DMS predicts that managers have incentive to manage earnings to meet or beat prior year's earnings.

\footnotetext{
${ }^{4}$ DMS provides some descriptive evidence on the discount rates firms use to estimate the fair value of retained interest. The fair value of the retained interest is used to allocate the carrying amount of the total securitized assets between the securitized and retained portions. Investigating these discount rates could provide direct evidence on the manipulation of the estimates because they are an input to fair value estimation. However, DMS does not attempt to relate the discount rate to evidence of earnings management, e.g., to the negative correlation between $S I$ and PSI.
} 
To test these predictions, DMS estimates the following equations

$$
\begin{aligned}
& S I=\alpha+\beta P S I+\gamma \text { CONTROLS } \\
& S I=\alpha+\beta \Delta P S I+\gamma \text { CONTROLS }
\end{aligned}
$$

where $S I$ is securitization income scaled by prior year book value of equity, $P S I$ is presecuritization income scaled by prior year book value of equity, and CONTROLS is a vector of control variables that includes: median SI for the firm's two-digit SIC code and year, adverse change divided by retained interest, idiosyncratic equity return volatility, disclosed discount rate used to estimate the fair value of the retained interest, cash flow from operations plus cash flow from investing less securitization proceeds scaled by book value of equity, and an indicator variable for whether the firm has more than one segment.

DMS estimates five specifications of equation (1) and in all five finds a strong negative relation, i.e., significance at the $1 \%$ level, between SI and PSI. In contrast, DMS finds a weak negative relation, i.e., significance at the $10 \%$ level, between $S I$ and $\triangle P S I$ in three of the five specifications of equation (2) and no significant relation in two of the five specifications. DMS interprets these findings as evidence that "managers use the flexibility available in fair value accounting rules to manage earnings.”

DMS interprets the evidence as indicating that managers manipulate fair value estimates. But it is not clear that the tests support this inference. The tests provide evidence of a negative correlation between SI and PSI, which is consistent with earnings smoothing, but do not address the source of this correlation. We offer two explanations for a negative correlation between SI and PSI that do not involve the manipulation of fair value estimates - "real” earnings management and a mechanical relation between SI and PSI.

\subsection{1 "Real” Earnings Management}


Non-zero securitization income is not, by itself, evidence that managers use the flexibility available in fair value accounting rules to manage earnings. First, securitization income can reflect the firm's economic income. Just as some firms have a competitive advantage in manufacturing cars, some firms have a competitive advantage in originating loans or other financial assets. For example, many mortgage brokers have a competitive advantage in originating mortgages in a particular locale. This advantage enables them to sell these mortgages to investors at prices above the broker's origination cost. In this case, securitization income captures the securitizing firm's economic income, e.g., information rents. Second, securitization income can reflect gains or losses on the securitized assets that were not previously recognized because the assets were measured using some form of historical cost-based accounting. In this case, securitization income results from historical cost accounting rules - under which gains and losses are not recognized until there is a transaction that triggers their recognition, not fair value accounting rules.

These potential sources of securitization income raise the possibility that firms could engage in "real" earnings management related to securitization income. By "real" earnings management we mean that firms enter into transactions that alter current period earnings, but do not manipulate fair value estimates. This raises the possibility that the findings in DMS could be explained by firms engaging in "real" earnings management. That is, real earnings management could result in a negative correlation between $S I$ and $P S I$ absent manipulation of fair value estimates.

Consider the follow scenario. Assume that Government Motors' primary business is selling automobiles, but it also has a consumer finance division. The firm forecasts a negative shock to income in the current quarter because of a decline in demand for automobiles. The firm 
decides to securitize some of its consumer loans and sell them, thereby lessening the negative shock to earnings. This will result in a negative correlation between securitization income and pre-securitization income, which DMS instead attribute to manipulating fair value estimates.

As explained above, the existence of securitization income could arise from two sources. First, assume Government Motors has a competitive advantage in originating loans. Upon forecasting a negative shock to income in the current quarter, Government Motors instructs its sales force to originate more loans. Because of its competitive advantage, securitizing these loans results in securitization gains, which offset the expected negative shock to earnings, and results in a negative correlation between securitization income and pre-securitization income. Second, alternatively assume Government Motors has existing consumer loans whose carrying amount is less than their market value. Government Motors decides to securitize these loans to trigger recognition of previously unrecognized gains, which also results in a negative correlation between securitization income and pre-securitization income. This “cherry picking” of unrecognized gains is a form of real earnings management because it involved no manipulation of fair value estimates - or any other accounting amounts. In both cases, the discretion exercised by management was the decision to engage in a securitization transaction to recognize gains to offset an expected negative shock to earnings, not the decision to manipulate fair value estimates. $^{5}$

\subsubsection{Mechanical Relation Between Securitization Income and Pre-Securitization Income}

\footnotetext{
5 The existence of competitive advantage or assets with unrecognized gains is an open empirical question. Dechow and Shakespeare (2009) finds that $40 \%$ of securitizations occur in the last month of the quarter, and, of these, nearly half occur in the last five days of the quarter. It is not known whether these securitized assets were newly originated, suggesting an end-of-quarter sales push to recognize gains associated with the firm's competitive advantage or with manipulation of accounting estimates, or were existing loans with unrecognized gains, suggesting last minute cherry picking.
} 
The findings in DMS also could be explained by the construction of SI and PSI. In particular, $S I$ and $P S I$ are scaled by prior year book value of equity. DMS motivates this scaling by stating that "equity is a more meaningful measure of capital than assets [for financial institutions] because assets under management can be large.” However, assuming that firms require capital to generate income, scaling by book value of equity, i.e., a proxy for capital, could result in $S I$ being mechanically negatively related to $P S I$. The intuition for this possibility is that if firms require capital to generate income, then the fraction of capital the firm uses for securitization projects will be one minus the fraction of capital it uses for non-securitization projects. That is, every dollar allocated to securitization activity is a dollar less allocated to nonsecuritization activity. For example, assume Government Motors has two lines of business. In the first line of business Government Motors manufactures automobiles, and in the second it originates and securitizes automobile loans. Management of Government Motors is faced with allocating capital across these two business lines.

Suppose the income stream of the firm is given by $I=r C$, where $I$ is income, $C$ is capital, and $r$ is the firm's rate of return. Suppose we decompose $C$ into the amount used for securitizations, $C_{s}$, and the amount used for non-securitizations, $C_{n}$, and construct the variables $S I$ and $P S I$ as

$$
S I=\operatorname{SecInc} /\left(C_{n}+C_{s}\right) \quad \text { and } \quad P S I=\text { PreSecInc } /\left(C_{n}+C_{s}\right)
$$

where SecInc is unscaled securitization income, given by $r C_{s}$, and PreSecInc is unscaled presecuritization income, given by $r C_{n}$. Even if the rates of return on securitization and nonsecuritization capital are identical, the slope coefficient in a regression of $S I$ on $P S I$ will be negative by construction. To see this note that 


$$
S I=\frac{r}{1+\frac{C_{n}}{C_{s}}} \quad \text { and } \quad P S I=\frac{r}{1+\frac{C_{s}}{C_{n}}}
$$

Thus, the former increases as the latter decreases, and vice versa. We refer to the potential for a natural negative correlation between $P S I$ and $S I$ induced by the firm's capital constraint, i.e., $C_{n}$ $+C_{s}=C$, as the "capital effect."

To assess the potential effect of the capital effect on the correlation between PSI and SI, we use a simulation. For the simulation, we generate random values of $r, C_{n}$, and $C_{s}$ according to the following uniform distributions: $C_{n} \sim \mathrm{U}[0,100], C_{s} \sim \mathrm{U}[0,100], r \sim \mathrm{U}[0.05,0.25]$. All variables and draws are independent. ${ }^{6}$ We generate values for 300 observations to approximate the same sample size in DMS and construct SI and PSI using equation (4). We then estimate a regression of the resulting $S I$ on the resulting $P S I$. We repeat the process 1,000 times and examine the empirical distributions of the 1,000 coefficient estimates and $t$-statistics. We repeat the same process for the regression of SI on $\triangle P S I$.

Table 1 presents the simulation results. Panel A presents the summary statistics from estimating the regression of SI on PSI. It reveals that the mean PSI coefficient is reliably negative (mean $\beta=-0.56$ ). In fact, we find that the entire distribution of $\beta$ lies below zero. The mean $t$-statistic is also reliably negative (mean $t(\beta)=-12.81)$. Perhaps even more importantly, the $1^{\text {st }}$ and $99^{\text {th }}$ percentiles of the $t(\beta)$ distribution are -10.00 and -16.20 . Thus, even with random data, the relation between $P S I$ and $S I$ is significantly negative. Panel B presents analogous statistics from estimating the regression of $S I$ on $\triangle P S I$. It reveals that the mean $\triangle P S I$

\footnotetext{
${ }^{6}$ The lower and upper supports of $r$ are based on the $25^{\text {th }}$ and $75^{\text {th }}$ percentiles of the descriptive statistics for return on equity reported in DMS. Because data on the amount of capital used in securitization and non-securitization activities are not available, for simplicity we scale $C_{n}$ and $C_{s}$ to range from 0 to 100 .
} 
coefficient is smaller than the mean $P S I$ coefficient in panel A, but it is also reliably negative (mean $\beta=-0.07$ ). In fact, panel $\mathrm{B}$ reveals that the $1^{\text {st }}$ and $95^{\text {th }}$ percentiles of the $\beta$ distribution lie below zero ( -0.18 and -0.001 , respectively). Similarly, the mean $t$-statistic is smaller than in panel $\mathrm{A}$, but again reliably negative (mean $t(\beta)=-2.24$ ). In addition, the $1^{\text {st }}$ and $50^{\text {th }}$ percentiles

of the $t(\beta)$ distribution are -6.21 and -2.08 , which suggests that fifty percent of the time there is a significant negative relation between $S I$ and $\triangle P S I$ in random data. The attenuation of the $t$ statistic for the coefficient on $\triangle P S I$ relative to that for the coefficient on PSI is consistent with the results reported by DMS. DMS finds $t$-statistics on PSI's coefficient that range from -12.42 to -10.80 (see DMS, Table 3 Panel A) and $t$-statistics on $\triangle P S I$ 's coefficient that range from 1.90 to -1.57 (see DMS, Table 3 Panel B). Collectively, we interpret the simulation evidence as suggesting that the capital effect can induce a mechanical negative correlation between $S I$ and $P S I$ and between $S I$ and $\triangle P S I$ on the order of the correlations reported in DMS.

\subsection{Securitization Income and CEO Pay}

Incentives are a necessary condition for earnings management (Schipper, 1989). If earnings management with regard to securitization gains is so pervasive that it occurs on average, then the incentives for such activities must be similarly pervasive. It is important for DMS to document that CEO pay is sensitive to securitization gains because the form of DMS's earnings management tests in equations (1) and (2) is based on the prediction that managers have incentives to inflate earnings using securitizations. To test this prediction, DMS estimates the following regression:

$$
\ln (\text { TotComp })=\alpha+\gamma_{1} \text { PSI }+\gamma_{2} S I+\gamma_{3} \text { CONTROLS }+\varepsilon
$$


where TotComp is total compensation and CONTROLS is a vector of control variables that includes: natural logarithm of total assets, an indicator for whether the firm operates in a regulated industry, and monthly equity returns for the fiscal year. DMS finds that the coefficients on $P S I$ and $S I$ are significantly positive and that the coefficients are not significantly different. $^{7}$

Finding a significant positive coefficient on $S I$ in equation (5) indicates that, on average, CEOs appear to be compensated for securitization income. This finding indicates that CEOs have incentives to increase securitization income. Finding that the coefficients on SI and PSI are not significantly different indicates that the CEO is compensated in equal amounts for each dollar of pre-securitization income and securitization income. This finding is consistent with three interpretations, which depend on one's priors about efficient contracting and the level of discretion in SI relative to that in PSI:

1. If one assumes that $S I$ is subject to more discretion than is $P S I$, then $\gamma_{1}=\gamma_{2}$ could be interpreted as indicating that the compensation committee does not understand the level of discretion involved in securitizations, i.e., $S I$ is subject to more discretion than PSI and contracts are inefficient.

2. If one assumes that contracting is efficient, then $\gamma_{1}=\gamma_{2}$ could be interpreted as indicating that $S I$ and $P S I$ are subject to the same level of discretion, i.e., $S I$ and $P S I$ are subject to similar discretion and contracts are efficient.

3. If one assumes that contracting is efficient and $S I$ is subject to more discretion than PSI, then $\gamma_{1}=\gamma_{2}$ could be interpreted as indicating that it is optimal to reward the CEO for $S I$

\footnotetext{
${ }^{7}$ Equation (5) does not permit the coefficient on securitization gains to vary with the level of earnings and, as such, assumes the incentive to report securitization income does not vary with level of non-securitization income. Thus, equation (5) does not permit tests of DMS's predictions that as the firm's securitization income increases there is "less incentive" to report a gain, and "that firms will have stronger incentives to boost discretionary gains when premanaged earnings fall short of prior year earnings.”
} 
even though it is discretionary, i.e., SI is subject to more discretion than PSI and

\section{contracts are efficient.}

Regardless, the findings inform us only about the incentives of the CEO and not whether fair value estimates or securitization gains are managed. That is, the findings do not inform us about the level of discretion in $S I$.

We are reluctant to believe that contracts are inefficient, i.e., that practitioners “do not appear to fully understand the application of fair value accounting rules.” Thus, we view the evidence as consistent with interpretation \#2 or \#3. ${ }^{8}$ The evidence indicates that managers have incentives to increase income from securitizations. However, whether this incentive arises as a result of the ignorance or intention of the compensation committee is unclear.

\subsection{The Role of Governance}

If earnings management is not desirable from the perspective of shareholders, then one can view earnings management as an agency problem in which managers extract rents from shareholders. ${ }^{9}$ Taking this view, we would expect to observe that both the outcome of the manipulation and the incentives for the manipulation vary with the level of corporate governance. Consistent with this, DMS investigates whether governance plays a role in mitigating earnings management and the incentives for earnings management. DMS uses four indicator variables to measure dimensions of governance: (1) whether a financial expert serves on the audit committee, i.e., board informativeness; (2) whether there is a female on the board, i.e., board heterogeneity; (3) whether more than $90 \%$ of the board are outside directors, i.e.,

\footnotetext{
${ }^{8}$ Distinguishing interpretations \#2 and \#3 also is confounded by the predictions and findings from the tests relating to the negative relation between $S I$ and $P S I$ discussed in Section 3.1. In particular, DMS attributes to earnings management the significant negative correlation between $S I$ and $P S I$. In equation (5), the coefficient on SI reflects the relation between $\ln (\operatorname{Tot} \operatorname{Comp})$ and the portion of $S I$ that is orthogonal to PSI. If discretion manifests in a negative correlation between $S I$ and $P S I$, then $\gamma_{1}$ does not reflect discretion in $S I$. As a result, finding $\gamma_{1}=\gamma_{2}$ is consistent with boards placing equal weight on PSI and the unmanaged component of $S I$.

${ }^{9}$ Earnings management is not necessarily undesirable from the perspective of shareholders (e.g., Fan, 2006).
} 
board independence; and (4) whether more than $50 \%$ of the board was elected before the CEO took office, i.e., board independence.

First, DMS examines whether the negative relations between $S I$ and $P S I$ and between $S I$ and $\triangle P S I$ vary with the level of the firm's governance. DMS finds that the correlation between SI and $P S I$ is significantly lower when more than $91 \%$ of the board are outsiders and when more than $50 \%$ of the board is elected before the CEO took office, but not so for the remaining two governance measures. DMS finds that the correlation between $S I$ and $\triangle P S I$ is significantly lower when more than $50 \%$ of the board is elected before the CEO took office, but not so for the remaining three measures. DMS interprets the findings as weak evidence for the prediction that there is less earnings management in firms with better governance.

Second, DMS examines whether incentives to report securitization gains vary with the level of governance. To test whether governance affects the incentives to report securitization gains, DMS estimates equation (5) after partitioning the sample into eight groups based on the four governance indicator variables. For all eight partitions, DMS finds that the coefficient on $S I$ is not significantly different from the coefficient on PSI.

Thus, DMS finds only weak evidence that earnings management varies with the level of governance and no evidence that the incentives to report securitization gains vary with the level of governance. This is somewhat puzzling because if, as DMS predicts, managers manipulate fair value estimates to increase earnings, why would a relatively independent and informed board not curtail this practice? Again, there are three alternative interpretations for these findings, and the tests in DMS are unable to distinguish among them:

1. Managers manipulate fair value estimates and even informed or independent boards of directors are ignorant or powerless to stop it. 
2. Managers manipulate fair value estimates and the board of directors is not ignorant or powerless, but chooses not to intervene.

3. Managers are not manipulating fair values.

Recall that DMS finds that compensation is equally sensitive to $S I$ and $P S I$ even when the board is independent and informed. The evidence suggests that informed boards, i.e., those most likely to understand securitizations, and independent boards, i.e., those that have the greatest capacity to intervene, do not intervene. Because we are reluctant to assume that contracting is inefficient, i.e. boards are ignorant, we view the evidence as inconsistent with the first interpretation. That is, we believe that alternative \#2 or \#3 is more plausible, i.e., either managers are not manipulating fair value estimates or, if they are, the board chooses not to intervene.

\subsection{The Relevance of Earnings Management Research for Financial Accounting Standard Setting}

Based on evidence of earnings management, it might be tempting to conclude that using fair value estimates in accounting is not desirable, i.e. is detrimental to investor welfare. However, we caution against drawing inferences about the desirability of a particular accounting method based on evidence of earnings management. Holthausen and Watts (2001) cautions against making standard-setting conclusions based on associations observed in the data. Holthausen and Watts (2001) notes that in order to do so, researchers must specify an objective of standard setting and how knowledge about a specific association observed in the data can help standard setters achieve that objective. Barth, Beaver, and Landsman (2001) explains how researchers can infer the objective of standard setting from the FASB's Conceptual Framework and how researchers can develop a link between a research design and the objective (see also, 
Barth, 2006). Although Holthausen and Watts (2001) and Barth, Beaver, and Landsman (2001)

focus on the value relevance literature, the same issues apply to the earnings management literature, the conservatism literature, and other empirical literatures that claim relevance for standard setting.

Fair value and 'gain on sale,' like all accounting amounts, can be manipulated. However, it would seem premature to suggest that evidence of earnings management associated with a particular accounting method suggests the method is not desirable. To use the language of Holthausen and Watts (2002, p. 29), evidence of earnings management or its absence is "not a sufficient condition for [the desirability of] an accounting standard.” To make a case against a particular accounting standard it is important to consider not only the costs and benefits of that standard, but also those of the alternatives. ${ }^{10}$ Estimating fair value allows for discretion, but perhaps discretion is welfare improving. Perhaps other measures would be easier to manipulate - even historical cost-based measures. Perhaps a manager always can find a way to manipulate accounting amounts. Wherever there is discretion in accounting - which is essentially everywhere - there is the opportunity for earnings management. If a manager manipulates accounting amounts, should we blame the accounting or the manager? The relation between managerial discretion and investor welfare is ambiguous and likely varies by setting. Thus, accounting standards should not be judged solely based on the level of discretion they permit.

\subsection{Conclusions and Directions for Future Research}

Dechow, Myers, and Shakespeare (2009, DMS) studies an interesting and timely issue discretion in income from asset securitizations. Asset securitizations are an important and growing economic activity and the accounting for securitizations is controversial and has been

\footnotetext{
${ }^{10}$ With regard to fair value accounting see Laux and Leuz (2009) for further discussion.
} 
criticized during the current financial crisis. DMS contributes to the asset securitization literature primarily by providing evidence that managers use asset securitizations to smooth earnings.

DMS interprets the evidence as indicating that the discretion exercised by managers relates to estimating fair value. However, more needs to be done before making that inference. From the tests and evidence in DMS it is not possible to discern whether the observed earnings management results from discretion in estimating the amount of securitization income, from discretion in determining which assets to securitize, or from discretion in business decisions. Each of these could result in earnings smoothing. However, these are very different sources of earnings management, and only one is associated with using discretion in estimating fair value. Regardless, we caution against inferring the desirability of any particular accounting method from earnings management research.

A productive avenue for future research on discretion in the accounting for asset securitizations would be to investigate directly the role of discretion in fair value estimates. Doing so would help distinguish the two sources of earnings management that confound the inference in DMS. For example, Dechow and Shakespeare (2009) finds that firms tend to securitize assets in the third month of the firm's fiscal quarter and interprets the evidence as indicating that managers use asset securitizations to increase quarterly earnings. That study does not seek to provide evidence on whether managers manipulate fair value estimates to increase earnings - it focuses solely on securitization volume. However, if, for example, one were to find that inputs to fair estimates in the third month are significantly different from inputs in other months, it could be suggestive that managers are manipulating fair value estimates. 
Recent changes in accounting standards might provide a greater opportunity to investigate the discretion in fair value estimates. For example, SFAS 157 (FASB, 2006) defines fair value, provides guidance on how to determine it, and requires more extensive disclosures about fair value than required previously. Perhaps these new disclosures can be used to construct more direct tests. In addition, SFAS 166 (FASB, 2009) requires retained interests in securitized assets to be measured initially at fair value. Perhaps this new requirement places greater focus on estimating the fair value of retained interest than was the case during DMS's sample period.

Another avenue for future research is to investigate whether securitization income reflects other forms of earnings management. DMS studies earnings smoothing, which is only one form of earnings management studied in the earnings management literature. For example, perhaps securitization income is used to meet analyst forecasts or hit bonus targets.

Accounting for asset securitizations is a potentially powerful setting in which to study earnings management. DMS is a step in helping us to understand the role of earnings management in this complex and controversial accounting setting. There is much more to understand and, thus, much to learn from future research. 


\section{References}

Barth, M., 2006. Research, standard setting, and global financial reporting. Foundations and Trends in Accounting 1, 71-165.

Barth, M., Beaver, W., Landsman, W., 2001. The relevance of the value relevance literature for financial accounting standard setting: another view. Journal of Accounting and Economics 31, 77-104.

Dechow, P., and C. Shakespeare, 2009. Do managers time securitization transactions to obtain accounting benefits? The Accounting Review 84, 99-132.

Fan, Q., 2007. Earnings management and ownership retention for initial public offering firms: theory and evidence. The Accounting Review 82, 27-64.

Financial Accounting Standards Board. 1993. Statement of Financial Accounting Standards No. 115: Accounting for Certain Investments in Debt and Equity Securities, Norwalk, CT:

FASB.

Financial Accounting Standards Board. 2000. Statement of Financial Accounting Standards No. 140: Accounting for Transfers and Servicing or Financial Assets and Extinguishments of Liabilities, Norwalk, CT: FASB.

Financial Accounting Standards Board. 2006. Statement of Financial Accounting Standards No. 157: Fair Value Measurements, Norwalk, CT: FASB.

Financial Accounting Standards Board. 2009. Statement of Financial Accounting Standards No. 166: Accounting for Transfers of Financial Assets - an amendment of FASB Statement No. 140, Norwalk, CT: FASB.

Holthausen, R., Watts, R., 2001. The relevance of the value relevance literature for financial accounting standard setting. Journal of Accounting and Economics 31, 3-77. 
Laux, C., Leuz, C., 2009. The crisis of fair-value accounting: Making sense of the recent debate. Accounting, Organizations and Society, In Press

Ryan, S. 2008. Accounting in and for the subprime crisis. The Accounting Review 83, 16051638.

Schipper, K., 1989. Commentary on earnings management. Accounting Horizons 3, 91-102. 


\section{Table 1. Simulation Results}

This table reports distribution statistics for the slope coefficient and respective $t$-statistic from simulating a regression of securitization income on pre-securitization income. We generate random values of securitization income $(S I)$ and pre-securitization income $(P S I)$ using the following formula:

$S I=r C_{s} /\left(C_{n}+C_{s}\right), P S I=r C_{n} /\left(C_{n}+C_{s}\right)$

where $C_{n} \sim \mathrm{U}[0,100], C_{s} \sim \mathrm{U}[0,100], \mathrm{r} \sim \mathrm{U}[0.05,0.25]$.

We generate independent values for 300 observations and regress SI on PSI. We retain slope coefficients i.e. $\beta$ and $t$-statistic estimates i.e. $t(\beta)$, and repeat the process 1,000 times. We repeat the same process for the regression of $S I$ on $\triangle P S I$. This procedure generates a sample of 1,000 coefficients and $t$-statistics. Panel A presents distribution statistics for the slope coefficient and $t$-statistics from regressing SI on PSI. Panel B presents distribution statistics for the slope coefficient and $t$-statistics from regressing $S I$ on $\triangle P S I$.

Panel A. Level Specification: $S I=\alpha+\beta P S I+\varepsilon$

\begin{tabular}{l|c|ccccccc}
\hline & & \multicolumn{8}{c}{ Distribution Percentiles } \\
Parameter & Mean & 1 & 5 & 10 & 50 & 90 & 95 & 99 \\
\hline$\beta$ & -0.56 & -0.65 & -0.63 & -0.61 & -0.56 & -0.51 & -0.49 & -0.47 \\
$t(\beta)$ & -12.81 & -16.20 & -15.13 & -14.58 & -12.74 & -11.09 & -10.68 & -10.00
\end{tabular}

Panel B. Change Specification: $S I=\alpha+\beta \Delta P S I+\varepsilon$

\begin{tabular}{l|c|ccccccc}
\hline & & \multicolumn{8}{c}{ Distribution Percentiles } \\
Parameter & Mean & 1 & 5 & 10 & 50 & 90 & 95 & 99 \\
\hline$\beta$ & -0.07 & -0.18 & -0.15 & -0.13 & -0.06 & -0.01 & -0.001 & 0.01 \\
$t(\beta)$ & -2.24 & -6.21 & -4.70 & -4.05 & -2.08 & -0.67 & -0.26 & 0.53 \\
\hline
\end{tabular}

